\title{
Management of Lower Extremity Vascular Trauma
}

\author{
Hasan B. Alam • Paul D. DiMusto
}

Published online: 22 January 2015

(C) Springer International Publishing AG 2015

\begin{abstract}
Management of vascular injuries, especially when they occur in combination with fractures, soft tissue loss, and nerve damage, is extremely challenging. Successful approach requires setting clear priorities, a logical plan of interventions, and close coordination between various subspecialty services. This chapter highlights the basic principles of vascular injury management that can be used by health care providers from a variety of backgrounds to save lives and limbs.
\end{abstract}

Keywords Vascular $\cdot$ Injuries $\cdot$ Shunts $\cdot$ Limb $\cdot$ Ischemia . Bleeding

\section{Introduction}

Major vascular injuries following trauma in the civilian settings are relatively rare. In a recent review of the National Trauma Data Bank (NTDB) from 2002 to 2010 that encompassed nearly 3.9 million patients, only $2.2 \%$ suffered a vascular injury [1]. The patients who suffered an isolated arterial injury made up $1.1 \%$ of the larger group. Older studies indicate that peripheral vascular injuries account for 40-75\% of vascular injuries treated in civilian trauma centers, with the majority resulting from penetrating trauma [2]. In the battlefield setting, injuries to the lower extremities are relatively common. In fact, the rate of vascular injury in modern combat

This article is part of the Topical Collection on Trauma to the Lower Extremities

H. B. Alam $(\bowtie) \cdot$ P. D. DiMusto

Sections of General (HBA) and Vascular (PDD) Surgery, Department of Surgery, University of Michigan Health System, Taubman Center 2920B, 1500 E. Medical Center Drive, Ann Arbor, MI 48109, USA e-mail: alamh@med.umich.edu is five times than that reported in previous wars, with the majority involving proximal/major vessels and nearly half requiring surgical repair/reconstruction [3]. Vascular injuries (arterial and venous) are also seen in patients with mangled extremities, and their management is especially challenging due to associated orthopedic trauma, soft tissue loss, nerve damage, and contamination. This chapter focuses on basic principles of early management and provides common sense strategies that can be used by a wide variety of surgical providers.

\section{Principles of Management}

It should be emphasized that patients with vascular injuries, like all other trauma patients, should be cared for according to the principles described in the Advanced Trauma Life Support Program. In addition, the management of vascular injuries focuses on some specific goals including early hemorrhage control, minimization of distal ischemia, restoration of perfusion, and prevention of compartment syndrome. Some of these issues are discussed in more detail below:

1. Hemorrhage Control: Vascular injuries of the extremities often present with massive bleeding (arterial, venous, or both), which must be immediately controlled. The most effective method depends upon the location/site of the injury, expertise level of the caregiver, and the resources available. The basic maneuver of direct digital compression works extremely well in most injuries and does not require any sophisticated tools. This should, therefore, be the first step. In the pre-hospital setting, more secure control can be obtained by prompt and proper application of tourniquets. A review of 10 years of data from a military registry showed that of 4,297 casualties with extremity trauma, $30 \%$ underwent application of 
tourniquets [4•]. Over this period, tourniquet use increased by tenfold, and survival rates improved markedly for casualties that had injuries amenable for tourniquets. Typical tourniquets are not effective for really proximal injuries [5], but in recent years, a number of junctional tourniquets have been developed, and two of these [Combat Ready Clamp ${ }^{\mathrm{TM}}$ (CRoCTM; http://www. combatmedicalsystems.com) and SAM Junctional Tourniquet ${ }^{\circledR}$ (SJT ${ }^{\circledR}$; http://www.sammedical.com/ products)] performed well when tested by military medics [6]. In addition, a number of advanced hemostatic dressings are now available that can be used to pack the wound to help with hemorrhage control [7•]. In our opinion, emergency medical personnel should be trained in the proper use of tourniquets and advanced hemostatic dressings. Once the patient reaches a facility where surgical expertise is available, additional maneuvers can be performed (if needed) to control the source of hemorrhage including application of vascular clamps to the injured vessels or deployment of intraluminal occlusive balloons [8]. In the most extreme situations, the aorta (thoracic or abdominal) can be controlled with the bedside application of the resuscitative endovascular balloon occlusion of the aorta (REBOA) devise [9]. The balloon-carrying catheter can be inserted using percutaneous techniques, typically via the femoral artery, advanced (without fluoroscopy) into the aorta, and inflated to achieve interruption of aortic flow below the balloon. In this way, REBOA functions essentially similar to an aortic cross-clamp that is applied during resuscitative thoracotomy. Although these tools are not yet widely available, courses have been developed to teach these new life-saving skills to the surgical community [10].

2. Damage Control Resuscitation: Damage control resuscitation (DCR) or hemostatic resuscitation has recently emerged as a potential solution for the prevention and reversal of trauma-associated coagulopathy (TAC) [11•, 12]. This approach advocates early hemorrhage control, permissive hypotension (until control of hemorrhage), avoidance of crystalloids, and early use of blood components such as fresh frozen plasma (FFP) and platelets (in $1: 1$ or $1: 2$ ratios). We are awaiting the results of a recently completed prospective randomized trial, but variations of this strategy have already entered the trauma practice [13•, 14-16]. It should, however, be emphasized that high ratio protocols do not improve survival in patients who do not require massive transfusion $(<10$ units of packed red blood cells in $24 \mathrm{~h}$ ) [17]. In fact, inappropriate infusion of plasma in the patients who are not massively bleeding may worsen the outcomes [18•]. We also know that development of clot is just the initial part of the process, and rapid breakdown of the clot may be equally detrimental. It has been shown that development of fibrinolysis is a highly lethal event in severely injured patients $[19,20]$, and treatment with blood products alone is incapable of reversing this process. Recent studies have demonstrated that early administration of tranexamic acid (TXA) improves survival in trauma patients [21••], especially in the setting of massive blood loss [22]. So, while the exact ratio of PRBC to FFP and platelets may be debatable, contemporary resuscitation practices have moved to early delivery of component therapy (and antifibrinolytics) in massively bleeding patients, using standardized protocols. However, it should be emphasized that resuscitation is an adjunct to early hemorrhage control and not a substitute. In a bleeding patient, initiating DCR is a great idea, but the eventual survival depends upon the ability (or inability) to obtain rapid and reliable hemorrhage control. In addition, prevention and active reversal of hypothermia (e.g., use of fluid warmers, body warming devices, etc.) and correction of acidosis and hypocalcemia are critically important during resuscitation.

3. Evaluation and Diagnostic Tests: There are quite a few studies in the literature comparing the relative merits of various diagnostic tests. The Eastern Association for the Surgery of Trauma has reviewed the literature and put together updated guidelines for the evaluation and management of penetrating lower extremity vascular trauma [23*0]. According to these guidelines, patients with $p$ enetrating trauma that have hard signs of arterial injury (pulse deficit, pulsatile bleeding, bruit, thrill, expanding hematoma) do not need any vascular imaging studies. These patients should be surgically explored as soon as possible (within $6 \mathrm{~h}$ ) to maximize the chances of limb salvage. A common mistake is to manage these patients the way we manage patients with atherosclerotic occlusive disease. Atherosclerosis is a diffuse (multilevel), chronic disease, whereas traumatic disruption is localized to the area of injury and is acute. In the vast majority of patients, the level of vascular injury matches the site of penetrating trauma, except in rare cases of multiple gunshot wounds or shotgun injuries. In addition, due to the chronic nature of atherosclerotic occlusion, there is often extensive collateral flow, which is absent in the traumatic disruption. Finally, the nature of occlusion is very different (plaque versus injured artery). Thus, in the presence of hard signs of vascular injury, these patients should be rushed to the operating room instead of wasting precious time obtaining vascular imaging studies. If needed, an ontable angiogram can always be performed during the operation. In patients with blunt trauma (or penetrating trauma with long bone fracture), reduction of the fracture with reassessment should be performed first, as the pulse loss could be due to arterial entrapment which may resolve with the reduction of fracture. Patients with soft 
signs (history of pre-hospital blood loss, diminished pulses, moderate hematoma, proximity to vessels, high risk fractures/dislocations, ipsilateral neurologic deficit) or ankle-brachial index $(\mathrm{ABI})<0.9$ are suitable candidates for imaging studies to rule out a vascular injury, with computed tomographic angiography (CTA) being the test of choice. Finally, patients with normal exam (and no hard or soft signs) and $\mathrm{ABI}>0.9$ do not need any additional workup for vascular injuries. Data from high-volume trauma centers supports these recommendations. For example, Inaba et al. [24] reported prospectively collected data over 20 months where 635 patients with extremity trauma underwent a structured exam, and hard signs were noted in $5.5 \%$. In this subgroup, $97 \%$ had vascular injuries that required an operation, whereas there were no missed injuries during follow-up in the patients that had no signs of vascular injury ( $83 \%)$. Of the patients, $11.5 \%$ had soft signs and they underwent multidetector CTA; excluding scans with artifacts due to retained missiles, the CTA had sensitivity and specificity of $100 \%$. As it is a noninvasive test that does not require the presence of an interventional radiologist, CTA is rapidly replacing conventional angiograms as the diagnostic test of choice. Currently, the role of Doppler pressure monitoring and duplex ultrasonography in diagnosing or excluding vascular injuries is not well defined.

4. Strategies to Minimize Ischemia Time: The best strategy to limit the ischemia time is to expedite operative interventions. It should be emphasized that the ischemia time includes the pre-hospital time (often including delays in inter-hospital transfers) as well as the time that it takes to actually repair the injury. As the goal is to restore blood flow within $6 \mathrm{~h}$, there is really no time to waste. One strategy that has recently gained momentum is the placement of temporary intravascular shunts (TIVS) to control the injury while restoring distal flow (arterial) and promoting drainage if needed (venous shunts). Good results have been reported by civilian [25•] as well as military surgeons [26] for a wide variety of vascular injuries. Typical indications are to control exsanguination ("damage control") or to maintain distal flow in the setting of combined orthopedic and vascular injuries (Gustillo IIIc fractures where skeletal stabilization may be required before vascular repair). Shunts are also a reasonable bailout option for surgeons who do not have the expertise to perform the definitive repair, as it can maintain limb viability during the transfer of patient to higher levels of care. There is no need for systemic anticoagulation with an indwelling TIVS. Even in complex battlefield injuries, managed in extremely challenging conditions, patency rates of $86 \%$ for proximal shunts have been reported with $>90 \%$ viability after eventual reconstruction [27]. Almost any tubing can be placed through the proximal and distal ends of a torn vessel and secured in place, but Javid, Argyle, and Pruitt-Inahara shuts are the most commonly used. It is logical to use the largest diameter shunt that can be placed in the injured vessel, with plans to return the patient to the operating room as soon as possible (preferably within $24 \mathrm{~h}$ ) for removal of the shunt and definitive repair of the injury. See Figs. 1, 2 , and 3 for examples.

5. Operative Principles for Open Repair: Basic principles include (1) obtaining adequate exposure, (2) proximal and distal control before exploring the vascular injury site, (3) preparing the potential vein harvest site, and (4) availability of vascular instruments, different sized Fogarty balloon catheters, and tubes for use as TIVS. Once the injured vessel is exposed, assessment should be made about the extent of damage. Simple arterial repairs fair better than grafts and should be considered if technically possible. For example, a simple arterial laceration from a knife can often be repaired primarily without significantly compromising the diameter. If there is concern about compromising the diameter of the vessel, then the injury can be repaired with a vein patch. However, blunt injuries, crush, gunshot wounds, etc. cause significant damage to the vessel wall which should be trimmed back to healthy tissues before proceeding with the repair. If the missing segment is short, a primary repair should be performed by anastomosing the spatulated edges of the vessel. However, larger segment vascular injuries should be replaced with reversed saphenous vein grafts. In poly-trauma situation, it should be kept in mind that amputated limbs can be a good source of venous grafts. However, in the setting of severely limited autologous conduit, prosthetic grafts can be used for limb salvage even in contaminated wounds [28]. Before the repair, good inflow and outflow should be ensured by removing any thrombus, and after the repair, good distal flow must be confirmed. In most cases, systemic anticoagulation is not feasible, so regional flushing with heparinized saline frequently is the only practical option. Our preference is to perform a completion on-table arteriogram, whenever possible. Early fourcompartment lower leg fasciotomy should be whenever possible considered when the total ischemia time is more than $4 \mathrm{~h}$ or if there are associated injuries (especially combined arterial and venous injuries) [29]. However, fasciotomy is not without complications, and the decision has to be made judiciously based on signs, ability to followup the patient closely after the operation, and expected outcomes. If prophylactic fasciotomy is not performed, compartment pressures should be closely monitored for the early detection of compartment syndrome.

The specialty background of the surgeon does not appear to be as important as their experience with vascular injuries. A recent multicenter study showed that that limb 
Fig. 1 Young man involved in a motorcycle accident with loss of distal pulses (hard sign).

Clockwise from left upper corner: (1) popliteal fossa laceration; (2) $\mathrm{X}$-ray showing fractures above and below the knee joint (floating knee); (3) patient was rushed to the operating room where exposure of the popliteal artery showed an area of ecchymosis (pointed out by the scissors) with pulses proximal to it and no pulses distally; (4) resected area of injury shows complete disruption of intima and media. This is a classic severe traction injury where only the adventitia was left intact. It is completely different from atherosclerotic occlusion, and a simple bypass without resection (or ligation) of this segment could result in development of large psueudoaneurysm

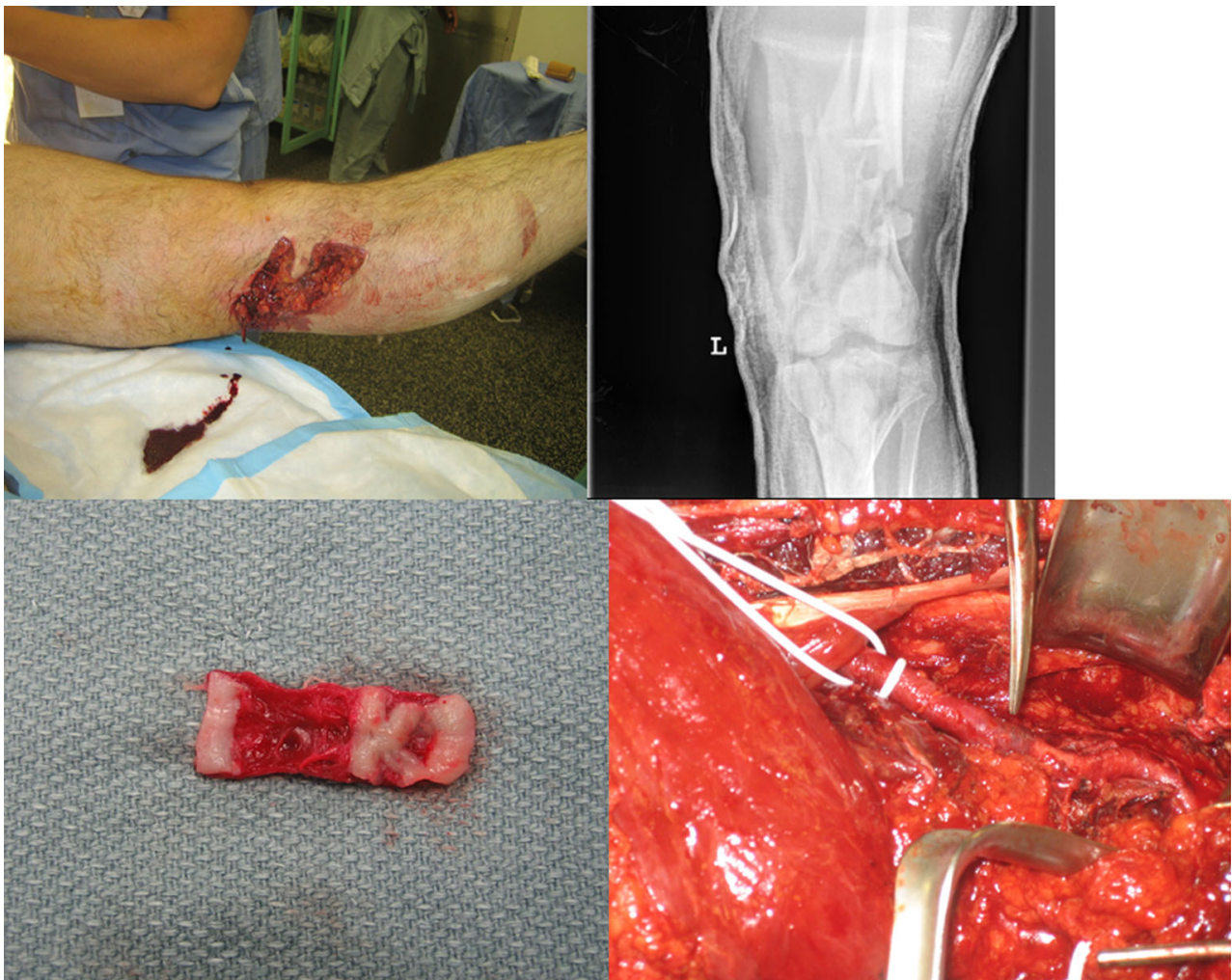

salvage following major vascular injury was independent of the surgeon's specialty training with the vast majority of complex repairs $(70 \%)$ being performed by the general surgeons [30].

Fig. 2 Intraoperative pictures of the patient shown in Fig. 1. Clockwise from left upper corner: (1) A temporary intravascular shunt in the popliteal artery that is tied in place with a silk suture. Note the extra length of the shunt to allow for reduction of the fracture. Also note that the silk suture is tied in a way to prevent excessive traction and dislodgement of the shunt. (2) View of shunt after reduction of the fracture. Note that the laxity in the shunt is gone after fracture reduction as the ends of the vessel have been pulled apart. This was the reason to not perform the definitive interposition graft before reduction and stabilization of the fracture fragments. (3) Xray shows external fixator reduction and stabilizing the fracture fragments. (4) Reverse saphenous vein interposition graft

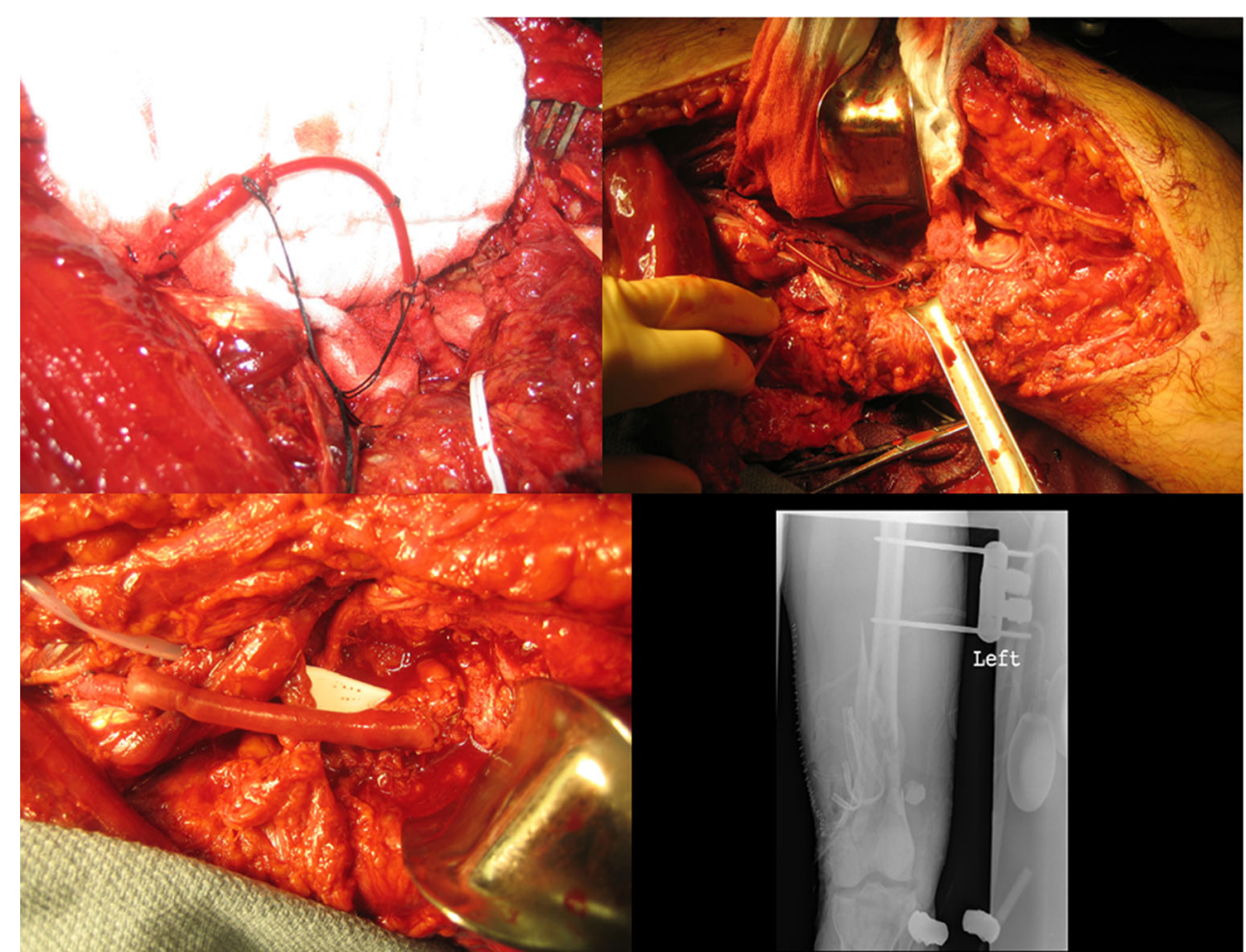


Fig. 3 Near amputation of a limb at the knee following high-speed motor vehicle accident.

Clockwise from left upper corner: (1) deformed lower extremity with large laceration at the knee and a tourniquet at the level of mid-thigh; (2) transected popliteal artery that was controlled and distal flow restored with a temporary intravascular shunt. Shunt was left in place without systemic anticoagulation for $24 \mathrm{~h}$ as it was unclear whether the limb was salvageable or not due to an unreliable physical exam. (3) External fixator stabilizing the fracture fragments and the knee. Note the prophylactic fourcompartment lower extremity fasciotomies. (4) Reverse saphenous vein interposition graft next day

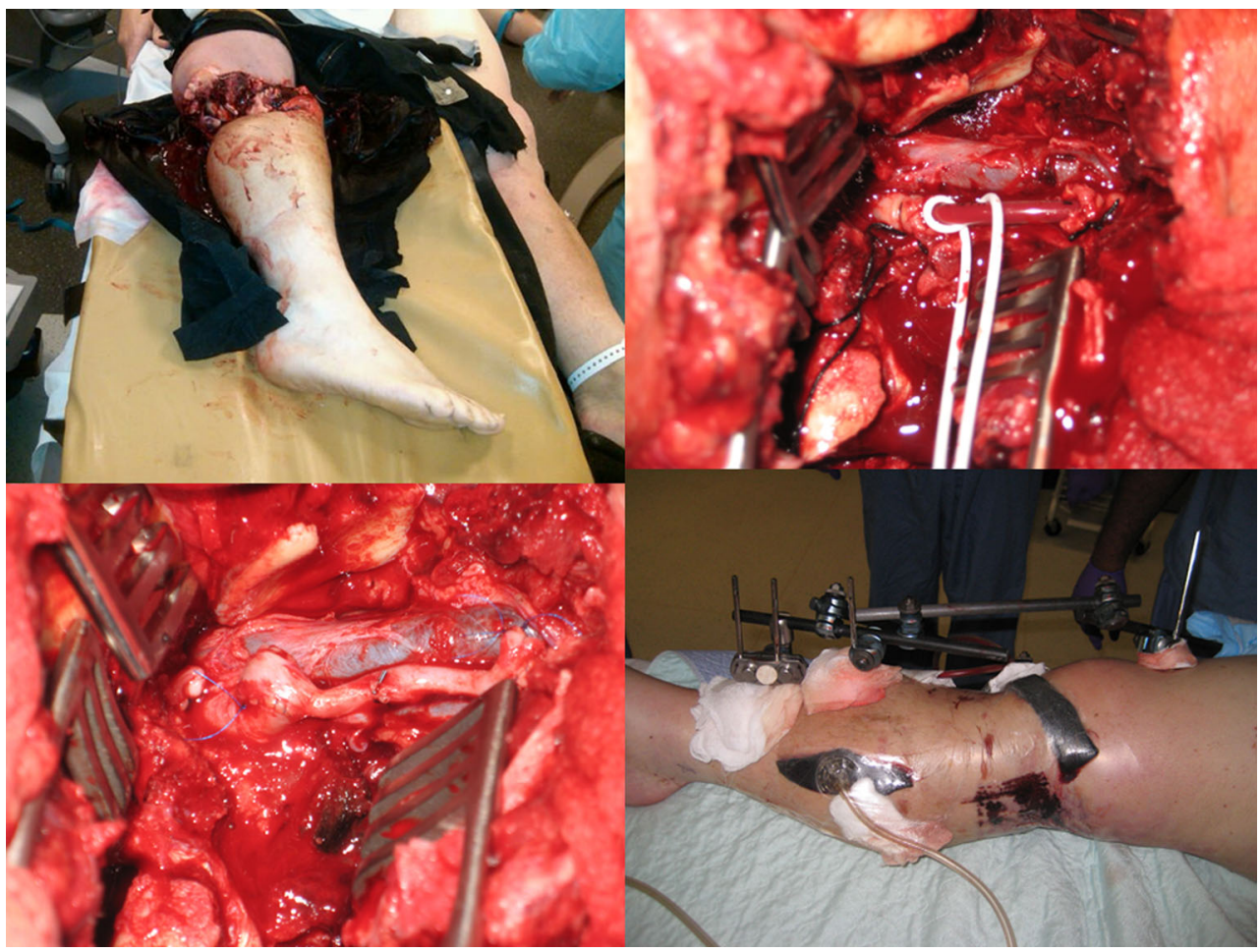

vascular injuries related to trauma [1, 31]. These endovascular interventions can range from temporary vascular control with a balloon, to embolization of a bleeding vessel, to covered stent repair of an injury [32]. An endovascular approach to a peripheral vascular injury in the trauma patient provides the advantage of remote access to the injured vessel, which can be crucial in difficult-to-expose anatomic areas, reduces the risk of injury to nearby nerves, and mitigates the need for surgically traversing already injured and, sometimes, devitalized tissue. Additionally, patients undergoing endovascular interventions can have decreased time in the operating room, reduced blood loss, and decreased mortality when compared to open surgical repair of similar injuries [1,31,33].

Both the Western Trauma Association and the Eastern Association for the Surgery of Trauma have issued guidelines on the management of lower extremity arterial trauma [23••, 34•]. Both acknowledge that data is scarce, and that there is no data to support the routine use of endovascular therapy following infra-inguinal trauma. However, both guidelines do endorse embolization of profunda branches or tibial vessels in appropriate patients. Despite a lack of strong data, three reviews of the $\mathrm{NTDB}^{\circledR}$ over time demonstrate the increase in endovascular therapy for vascular trauma. The first review examined the database from 1997, when the first endovascular repair was recorded in the database, to 2003 and included all arterial injury codes, not just peripheral [31]. These authors found that $2.2 \%$ of patients with arterial injury were treated with endovascular intervention and that these patients had lower Injury Severity Scores (ISS) and fewer associated injuries than the patients who underwent open repair. However, after controlling for ISS, age, associated injuries, and total ICU days, there was an overall survival advantage for endovascular repair. They also noted that the use of endovascular treatment increased over the study period from four cases in 1997 to 107 in 2003.

Another group looked at the trend in endovascular therapy in the NTDB from 2002 to 2010 [1]. They demonstrated a significant increase in endovascular therapy from $0.3 \%$ in 2002 to $9 \%$ in 2010, with the most clinically significant increase in patients suffering blunt trauma. In terms of specific vascular territories, endovascular treatment of the internal iliac artery went from 8 to $40 \%$ and the common and external iliac arteries from 0.4 to $20 \%$. The highest percentage of patients undergoing endovascular therapy were those with ISS scores 31-50. And again, the patients who underwent endovascular therapy had a significantly lower in-hospital mortality rate of $12.9 \%$ compared to $22.4 \%$ in those undergoing open repair. A similar review, but specific to peripheral arterial trauma (both upper and lower extremity), was conducted by Worni et al. and looked at the NTDB from 2007 to 2009 [35]. They found that $5.9 \%$ of the patients with extremity vascular injuries underwent endovascular repair. These patients tended to have higher ISS, were older, had more comorbid illness, and had more lower extremity arterial injury than the $94 \%$ who underwent open repair. They did not find a significant 
difference in in-hospital mortality between the groups after risk adjustment; however, those undergoing endovascular repair had a significantly fewer wound complications and a shorter length of hospital stay.

Covered stents are an attractive option for the management of peripheral arterial injury, particularly in areas that are difficult to expose surgically. A series of 62 patients with upper and lower extremity arterial trauma treated with a covered stent was reported by White et al. [36]. Thirty-three patients had iliac artery injury, while 11 involved the femoral. The 1year exclusion rate for iliac lesions was $91 \%$ but only $62 \%$ for femoral. However, the 1-year primary patency rates for stents in the iliac artery were 76 and $86 \%$ for femoral artery stents. The most common adverse events were stenosis in $4.8 \%$ of the entire cohort and stent graft occlusion, which occurred early in $6.5 \%$ and late in $1.6 \%$ of the entire cohort. Fifteen percent required surgical bypass within 1 year for various indications. A small study examined the use of covered stents in lower extremity arterial injury with combined skeletal injury as definitive repair prior to orthopedic fixation compared to placing a shunt with later open surgical repair after bony fixation in 16 patients [37]. These investigators found that the use of covered stents significantly reduced ischemic time and operative time. All stents as well as the open surgical grafts were patent at 3 months. Other case reports confirm that both bare metal and covered stents can be successfully used to treat arterial disruptions, dissections, and pseudoaneurysms of the iliac, superficial femoral, popliteal, and even the tibial artery [38-42]. However, robust longterm data on the patency of these stents used for trauma is lacking. Given that the typical trauma patient is younger than those treated with stents for occlusive disease, long-term patency is an important consideration to keep in mind.

Other case reports demonstrate that embolization using coils or other materials can also be successfully performed for persistent bleeding or pseudoaneurysms from branches of the superficial femoral or profunda arteries, as well as the tibial arteries, consistent with the published guidelines [39, 43, 44]. Endovascular recanalization of an occluded tibial artery has also been reported [45].

Endovascular intervention does have inherent limitations. The inability to cross the lesion with a wire is considered an absolute contraindication, except in the case of embolization. Insufficient proximal and distal fixation points for a stent, need for stent placement in a mobile area such as across a joint, the inability to anticoagulate the patient due to other injuries, need for open repair of other injuries in the same area, a hemodynamically unstable patient, and a lack of immediate endovascular supplies and expertise are all relative contraindications to endovascular treatment depending on the injury and hospital environment $[33,35]$. Having an inventory of long sheaths, exchange length wires, balloons, bare metal, and covered stents in a wide range of sizes, and embolization coils is recommended for expedient and successful endovascular management of peripheral injuries [33]. In summary, there is limited evidence for the use of endovascular treatment of lower extremity arterial injuries. Despite this, there has been an increase in its use over the last 15 years and is correlated with a decrease in mortality and length of hospital stay. Arterial dissections, pseudoaneursyms, and even some transections can be successfully managed using endovascular techniques. The limited outcomes available are comparable or better than those for open surgical repair; however, the data is not robust. The patients that are best served by endovascular rather than open treatment are those who have injuries in difficult-to-expose anatomic areas, extensive soft tissue injury over the area of vascular injury, higher ISS, a large number of concomitant injuries, and significant medical comorbidities.

\section{Conclusions}

Priorities in the management of these complex patients include delivery of early trauma care, along with prompt control of hemorrhage using the simplest applicable method (e.g., manual compression or tourniquet), damage control resuscitation, and prompt surgical evaluation. If the surgeon has the required skill set, then a definitive repair of the vascular injury should be performed quickly to minimize the limb ischemia time. Otherwise, a TIVS should be placed, whenever possible, and the patient transferred to a higher level of care.

\section{Compliance with Ethics Guidelines}

Conflict of Interest Hasan B. Alam and Paul D. DiMusto declare that they have no conflicts of interest.

Human and Animal Rights and Informed Consent This article does not contain any studies with human or animal subjects performed by any of the authors.

\section{References}

Papers of particular interest, published recently, have been highlighted as:

- Of importance

•. Of major importance

1. Branco BC, DuBose JJ, Zhan LX, Hughes JD, Goshima KR, Rhee $\mathrm{P}$, et al. Trends and outcomes of endovascular therapy in the management of civilian vascular injuries. J Vasc Surg. 2014;60: 1297-307.

2. Feliciano DV, Moore FA, Moore EE, West MA, Davis JW, Caocanour CS, et al. Evaluation and management of peripheral vascular injury part 1 . Western Trauma Association/critical decisions in trauma. J Trauma. 2011;70:1551-6. 
3. White JM, Stannard A, Burkhardt GE, Eastridge BJ, Blackbourne LH, Rasmussen TE. The epidemiology of vascular injury in the wars in Iraq and Afghanistan. Ann Surg. 2011;253(6):1184-9.

4. Kragh JF Jr, Dubick MA, Aden JK, McKeague AL, Rasmussen TE, Baer DG, Blackbourne LH. U.S. Military use of tourniquets from 2001 to 2010. Prehosp Emerg Care. 2014 Nov 24. [Epub ahead of print] This paper presents the data summarizing a decade of tourniquet use by the military in the battlefield.

5. Kragh Jr JF, Dubick MA, Aden 3rd JK, McKeague AL, Rasmussen TE, Baer DG, et al. U.S. Military experience with junctional wounds in war from 2001 to 2010. J Spec Oper Med. 2013;13(4): 76-84.

6. Kragh Jr JF, Parsons DL, Kotwal RS, Kheirabadi BS, Aden 3rd JK, Gerhardt RT, et al. Testing of junctional tourniquets by military medics to control simulated groin hemorrhage. J Spec Oper Med. 2014;14(3):58-63.

7. Bennett BL, Littlejohn LF, Kheirabadi BS, Butler FK, Kotwal RS, Dubick MA, et al. Management of external hemorrhage in tactical combat casualty care: chitosan-based hemostatic gauze dressingsTCCC guidelines-change 13-05. J Spec Oper Med. 2014;14(3):4057. Expert opinion and recommendations are provided about the use of advanced hemostatic dressings.

8. Holcomb JB, Fox EE, Scalea TM, Napolitano LM, Albarado R, Gill B, et al. Current opinion on catheter-based hemorrhage control in trauma patients. J Trauma Acute Care Surg. 2014;76(3):888-93.

9. Brenner ML, Moore LJ, DuBose JJ, Tyson GH, McNutt MK, Albarado RP, et al. A clinical series of resuscitative endovascular balloon occlusion of the aorta for hemorrhage control and resuscitation. J Trauma Acute Care Surg. 2013;75(3):506-11.

10. Villamaria CY, Eliason JL, Napolitano LM, Stansfield RB, Spencer JR, Rasmussen TE. Endovascular Skills for Trauma and Resuscitative Surgery (ESTARS) course: curriculum development, content validation, and program assessment. J Trauma Acute Care Surg. 2014;76(4):929-35.

11. Alam HB, Velmahos GC. New trends in resuscitation. Curr Probl Surg. 2011;48:531-64. A review of resuscitation data, including information about Damage Control Resuscitation.

12. Dutton RP. Haemostatic resuscitation. Br J Anaesth. 2012;109 Suppl 1:i39-46.

13. Holcomb JB, Del Junco DJ, Fox EE, Wade CE, For the PROMMTT Study Group, et al. The Prospective, Observational, Multicenter, Major Trauma Transfusion (PROMMTT) study: comparative effectiveness of a time-varying treatment with competing risks. Arch Surg. 2012;15:1-10. A large multi-center study comparing various ratios of blood component therapy.

14. Holcomb JB, Wade CE, Michalek JE, et al. Increased plasma and platelet to red blood cell ratios improves outcome in 466 massively transfused civilian trauma patients. Ann Surg. 2008;248(3):447-58.

15. Holcomb JB, Zarzabal LA, Michalek JE, Kozar RA, et al. Increased platelet:RBC ratios are associated with improved survival after massive transfusion. J Trauma. 2011;71(2 Suppl 3):S318-28.

16. Inaba $\mathrm{K}$, Lustenberger $\mathrm{T}$, Rhee $\mathrm{P}$, Holcomb JB, Blackbourne LH, Shulman I, et al. The impact of platelet transfusion in massively transfused trauma patients. J Am Coll Surg. 2010;211(5):573-9.

17. Sambasivan CN, Kunio NR, Nair PV, et al. High ratios of plasma and platelets to packed red blood cells do not affect mortality in nonmassively transfused patients. J Trauma. 2011;71(2 Suppl 3): S329-36.

18. Inaba K, Branco BC, Rhee P, Blackbourne LH, Holcomb JB, Teixeira PG, et al. Impact of plasma transfusion in trauma patients who do not require massive transfusion. J Am Coll Surg. 2010;210(6):957-65. This paper describes the adverse effects of unnecessary plasma transfusion.

19. Ives $\mathrm{C}$, Inaba K, Branco BC, Okoye O, Schochl H, Talving P, et al. Hyperfibrinolysis elicited via thromboelastography predicts mortality in trauma. J Am Coll Surg. 2012;215(4):496-502.
20. Cotton BA, Harvin JA, Kostousouv V, Minei KM, Radwan ZA, Schöchl H, et al. Hyperfibrinolysis at admission is an uncommon but highly lethal event associated with shock and prehospital fluid administration. J Trauma Acute Care Surg. 2012;73(2):365-70.

21.• CRASH-2 trial collaborators. Effects of tranexamic acid on death, vascular occlusive events, and blood transfusion in trauma patients with significant haemorrhage (CRASH-2): a randomised, placebocontrolled trial. Lancet. 2010;376:23-32. A large multi-center, international, prospective randomized trial including $>20,000$ patients.

22. Morrison JJ, Dubose JJ, Rasmussen TE, Midwinter MJ. Military Application of Tranexamic Acid in Trauma Emergency Resuscitation (MATTERs) study. Arch Surg. 2012;147(2):113-9.

23.• Fox N, Rajani RR, Bokhari F, Chiu WC, Kerwin A, Seamon MJ, et al. Evaluation and management of penetrating lower extremity arterial trauma: an Eastern Association for the Surgery of Trauma practice management guideline. J Trauma Acute Care Surg. 2012;73(5 Suppl 4):S315-20. Evidenced based guidelines.

24. Inaba K, Branco BC, Reddy S, Park JJ, Green D, Plurad D, et al. Prospective evaluation of multidetector computed tomography for extremity vascular trauma. J Trauma. 2011;70(4):808-15.

25. Subramanian A, Vercruysse G, Dente C, Wyrzykowski A, King E, Feliciano DV. A decade's experience with temporary intravascular shunts at a civilian level I trauma center. J Trauma. 2008;65(2):31624. Largest civilian report of temporary shunt use.

26. Gifford SM, Aidinian G, Clouse WD, Fox CJ, Porras CA, Jones WT, et al. Effect of temporary shunting on extremity vascular injury: an outcome analysis from the Global War on Terror vascular injury initiative. J Vasc Surg. 2009;50(3):549-55.

27. Rasmussen TE, Clouse WD, Jenkins DH, Peck MA, Eliason JL, Smith DL. The use of temporary vascular shunts as a damage control adjunct in the management of wartime vascular injury. $\mathbf{J}$ Trauma. 2006;61(1):8-12.

28. Vertrees A, Fox CJ, Quan RW, Cox MW, Adams ED, Gillespie DL. The use of prosthetic grafts in complex military vascular trauma: a limb salvage strategy for patients with severely limited autologous conduit. J Trauma. 2009;66(4):980-3.

29. Branco BC, Inaba K, Barmparas G, Schnüriger B, Lustenberger T, Talving $\mathrm{P}$, et al. Incidence and predictors for the need for fasciotomy after extremity trauma: a 10-year review in a mature level I trauma centre. Injury. 2011;42(10):1157-63.

30. Shackford SR, Kahl JE, Calvo RY, Shackford MC, Danos LA, Davis JW, et al. Limb salvage after complex repairs of extremity arterial injuries is independent of surgical specialty training. $\mathrm{J}$ Trauma Acute Care Surg. 2013;74(3):716-23.

31. Ruben BC, Whitten MG, Sarfati M, Kraiss LW. Increasing use of endovascular therapy in acute arterial injuries: analysis of the National trauma Data Bank. J Vasc Surg. 2007;46:1222-6.

32. Doody O, Given MF, Lyon SM. Extremities - indications and techniques for treatment of extremity vascular injuries. Inj, Int $\mathrm{J}$ Care Injured. 2008;39:1295-303.

33. Johnson CA. Endovascular management of peripheral vascular trauma. Semin Interv Radiol. 2010;27:38-43.

34. Feliciano DV, Moore EE, West MA, Moore FA, Davis JW, Cocanour CS, et al. Western Trauma Association critical decisions in trauma: evaluation and management of peripheral vascular injury, part II. J Trauma Acute Care Surg. 2013;75(3):391-7. Guidelines for management of vascular trauma.

35. Worni M, Scarborough JM, Gandhi M, Pietrobon R, Shortell CK. Use of endovascular therapy for peripheral arterial lesions: an analysis of the National Trauma Data Bank from 2007 to 2009. Ann Vasc Surg. 2013;27:299-305.

36. White R, Krajcer Z, Johnson M, Williams DM, Bacharach M, O'Malley E. Results of a multicenter trial for the treatment of traumatic vascular injury with a covered stent. J Trauma. 2006;60: 1189-96. 
37. Simmons JD, Walker WB, Gunter III JW, Ahmed N. Role of endovascular grafts in combined vascular and skeletal injuries of the lower extremity: a preliminary report. Arch Trauma Res. 2013;2(1):40-5.

38. Stewart DK, Brown PJ, Tinsley Jr EA, Hope WW, Clancy TV. Use of stent grafts in lower extremity trauma. Ann Vasc Surg. 2011;25: 264.e9-.e13.

39. Franz RW, Shah KJ, Halaharvi D, Franz ET, Hartman JF, Wright ML. A 5-year review of management of lower extremity arterial injuries at an urban level I trauma center. J Vasc Surg. 2011;53: 1604-10.

40. Piffaretti G, Tozzi M, Lomazzi C, Rivolta N, Caronno R, Lagana D, et al. Endovascular treatment for traumatic injuries of the peripheral arteries following blunt trauma. Inj, Int J Care Injured. 2007;38: 1091-7.
41. Joglar F, Kabutey NK, Maree A, Farber A. The role of stent grafts in the management of traumatic tibial artery pseudoaneursyms: case report and review of the literature. Vasc Endovasc Surg. 2010;44(5):407-9.

42. Desai SS, DuBose JJ, Parham CS, Charlton-Ouw KM, Valdes J, Estrea AL, et al. Outcomes after endovascular repair of arterial trauma. J Vasc Surg. 2014;60:1309-14.

43. Rosa P, O’Donnell SD, Goeff JM, Gillespie DL, Starnes B. Endovascular management of a peroneal artery injury due to a military fragment wound. Ann Vasc Surg. 2003;17:678-81.

44. Arthurs ZM, Sohn VY, Starnes BW. Vascular trauma: endovascular management and techniques. Surg Clin N Am. 2007;87:1179-92.

45. Alvarez-Tostado J, Tulsyan N, Butler B, Rizzo A. Endovascular management of acute critical ischemia secondary to blunt tibial artery injury. J Vasc Surg. 2006;44:1101-3. 